\title{
Energia como temática no Ensino de Ciências da Natureza: uma abordagem a partir de experimentações virtuais
}

\author{
La energía como tema en la enseñanza de las ciencias naturales: una
}

\author{
aproximación desde experimentos virtuales
}

Energy as a theme in the Teaching of Natural Sciences: an approach from virtual experiments

\author{
Ticiane da Rosa Osório ${ }^{1}$ \\ Vitor Garcia Stoll ${ }^{2}$ \\ Márcio Marques Martins ${ }^{3}$
}

\begin{abstract}
Resumo
Este artigo apresenta um recorte de uma oficina desenvolvida com um grupo de acadêmicos integrantes do Programa Institucional de Bolsa de Iniciação à Docência (PIBID) de um curso de Licenciatura em Ciências da Natureza de uma Universidade Federal do sul do Brasil. Objetivou-se abordar a temática Energia por meio de duas experimentações, disponíveis no software PhEt. Metodologicamente, esta pesquisa se caracteriza como qualitativa, tendo como base a experimentação investigativa. Os dados empíricos foram obtidos por meio da aplicação de pré e pós-teste e foram submetidos à Análise de Conteúdo. Os resultados demonstraram que a experimentação investigativa possibilitou construir caminhos educativos para além da autonomia e do trabalho em equipe, pois a utilização do aplicativo foi caracterizada como um suporte na abordagem e desenvolvimento do tema Energia em função do contexto real dos estudantes, visto que, geralmente, esse conceito é apresentado de forma abstrata e descontextualizado.
\end{abstract}

Palavras-Chave: Energia. Experimentação. Tecnologias.

\section{Resumen}

Este artículo presenta un taller desarrollado con un grupo de académicos del Programa de Becas Institucionales de Iniciación a la Enseñanza (PIBID) de un curso de Licenciatura en Ciencias Naturales de una universidad federal en el sur de Brasil. El objetivo era abordar el tema de la Energía a través de dos experimentos, disponibles en el software PhEt. Metodológicamente, esta investigación se caracteriza por ser cualitativa, basada en la experimentación investigativa. Los datos empíricos se obtuvieron mediante la aplicación de pruebas previas y posteriores y se enviaron a Análisis de contenido. Los resultados mostraron que la experimentación investigativa permitió construir caminos educativos más allá de la autonomía y el trabajo en equipo, ya que el uso de la aplicación se caracterizó como un apoyo en el enfoque y desarrollo del tema de Energía de acuerdo con el contexto real de los estudiantes, ya que, en general, este concepto se presenta de manera abstracta y descontextualizada.

Palabras claves: Energía. Experimentación. Tecnologías.

\footnotetext{
1 Licenciada em Ciências da Natureza; Universidade Federal do Pampa; Dom Pedrito, RS, Brasil; ticiani_dp@hotmail.com.

${ }^{2}$ Licenciado em Ciências da Natureza; Afiliação; Universidade Federal do Pampa; Dom Pedrito, RS, Brasil; vitorgarciastoll@gmail.com.

${ }^{3}$ Doutor em Química; Universidade Federal do Pampa; Bagé, RS, Brasil; marsjomm@gmail.com.
} 


\begin{abstract}
This article presents an excerpt from a workshop developed with a group of academic members of the Institutional Scholarship Program for Initiation to Teaching (PIBID) of a degree course in Natural Sciences at a federal university in southern Brazil. The objective was to approach the Energy theme through two experiments, available in the PhEt software. Methodologically, this research is characterized as qualitative, based on investigative experimentation. Empirical data were obtained through the application of pre and post-tests and were submitted to Content Analysis. The results showed that the investigative experimentation made it possible to build educational paths beyond autonomy and teamwork, since the use of the application was characterized as a support in the approach and development of the theme of Energy according to the real context of the students, since, generally, this concept is presented in an abstract and decontextualized way.
\end{abstract}

Keywords: Energy. Experimentation. Technologies.

\title{
1. Introdução
}

Ao longo dos séculos a humanidade foi descobrindo, construindo, adaptando e modificando suas invenções, devido a diversidade de técnicas e descobertas que foram surgindo ao decorrer das diferentes épocas da história humana. Como exemplo, pode-se destacar a criação dos utensílios construídos a partir da pedra, o domínio do fogo, as pinturas rupestres e a linguagem na qual utilizamos para comunicação nos dias de hoje. Desse modo, dentre a grande diversidade de inovações e descobertas, esses exemplos supracitados foram essenciais para suprir as necessidades humanas ao longo do cenário evolutivo (PONTE, 2000).

De fronte a essas inovações, sabe-se que na atualidade são destacadas as Tecnologias de Informação e Comunicação (TIC) como principal elemento de integração social, pois são construídas com base nas relações existentes entre as pessoas. Mendes (2008) define as TIC como um conjunto de recursos tecnológicos que podem proporcionar uma comunicação, automação e diversificação em diversos ramos, abrangendo desde o ensino até as pesquisas científicas.

A disseminação e o uso das TIC em inúmeras áreas profissionais como no jornalismo, na administração, nas práticas médicas, na gestão de grandes empresas, têm auxiliado na evolução, agilidade e organização de diversas atividades. Na educação e no ensino, esta ferramenta objetiva principalmente a investigação científica por meio de pesquisas, reproduções de fenômenos, ampliação de conhecimentos, entre tantas outras, já que o avanço das TIC e suas contribuições são evidentes no contexto de sala de aula (PONTE, 2000; MENDES, 2008).

No entanto, vale destacar que a utilização das mesmas deve ser idealizada de forma coerente e compromissada, de modo que possibilite ao professor elaborar suas atividades de forma estruturada e bem pensada. As TIC quando empregadas de maneira correta podem 
estimular nos estudantes, de todos os níveis de ensino, o interesse, a curiosidade e o despertar científico para os assuntos abordados, e assim propiciar a estes um entendimento sobre os conceitos científicos em voga.

Dentro deste contexto, um dos principais feitos da humanidade foi o desenvolvimento tecnológico, que cresce expressivamente em consequência da globalização e da modernidade. Tavares e colaboradores (2013) argumentam em seu estudo que este crescimento se deve ao fato da diversidade de ferramentas e sua grande utilização como: televisores, celulares, computadores, entre outros aparelhos que emergem cotidianamente.

Para muitas pessoas, o uso de aparelhos celulares é fundamental nas atividades do dia a dia, tais como o despertador, a leitura de notícias nas redes sociais ou em sites especializados, as realizações de compras virtualmente e também a utilização para responder $e$-mails e assistir filmes, vídeos e etc. Por estes e tantos outros motivos, cada vez mais pessoas de todas as idades fazem uso dos recursos disponibilizados pelas tecnologias digitais. $\mathrm{O}$ emprego dos dispositivos móveis está mais associado, principalmente aos jovens, que buscam maior praticidade e melhores ferramentas, seja para uso pessoal ou profissional.

De acordo com a proporção em que as tecnologias digitais avançam no mundo globalizado, há indícios que sua disseminação chega aos espaços educativos e consequentemente nas diferentes metodologias de ensino, como uma demanda emergente do atual cenário social. Uma vez que, “[...] o cognitivo do ser humano está sendo intermediado por aparelhos tecnológicos, onde tais tecnologias estão ampliando o potencial intelectual do ser humano" (TAVARES et al., 2013, p. 156). As tecnologias digitais são excelentes recursos para a demonstração e abordagem de conteúdos e conceitos científicos abstratos, como exemplo a Energia, que é considerada umas das temáticas mais complexas que constituem o currículo de Ciências (GASPAR, 2009; MORTIMER; AMARAL, 1998).

Assim, sugere-se que os professores, especialmente os educadores de Ciências da Natureza, repensem na organização de propostas conceituais e metodológicas “"...] alicerçadas nas concepções científicas, favorecendo uma articulação e reestruturação das ideias apresentadas pelos alunos em meio às novas que são estabelecidas durante o processo de ensino" (SOUZA; JUSTI, 2010, p. 2). Ainda, é pertinente ressaltar que a articulação de suas ideias seja direcionada para que os estudantes percebam que a Energia seja compreendida pelas Ciências, Química, Física e Biologia, como integra e que é apenas separada no currículo para estabelecer uma organização do aprendizado. Esta necessidade está expressa nos Parâmetros Curriculares Nacionais (PCN) quando mencionam: 


\begin{abstract}
A energia é um exemplo importante de um conceito comum às distintas ciências, instrumento essencial para descrever regularidades da natureza e para aplicações tecnológicas. Na Física, pode ser apresentada em termos do trabalho mecânico necessário para impelir ou para erguer objetos, quando se calcula a energia cinética do movimento de um projétil ou veículo, ou a energia potencial da água numa barragem. [...] A falta de unificação entre os conceitos de energia pode resultar em uma "colcha de retalhos energética", a ser memorizada, das energias mecânica e térmica, luminosa, sonora, química, nuclear e tantos outros adjetivos, alguns pertinentes, outros não. Na Biologia e na Química, as energias não são menos importantes e nem menos variadas em suas designações e, no fundo, se trata da mesma energia da Física. [...] É preciso um esforço consciente dos professores das três disciplinas para que o aluno não tenha de fazer sozinho a tradução dos discursos disciplinares ou, o que é pior, concluir que uma energia não tem nada a ver com a outra (BRASIL, 2002, p. 29).
\end{abstract}

Conforme o excerto destacado, percebe-se a importância da interação entre os conceitos estabelecidos sobre o ensino do tema Energia nos componentes curriculares das Ciências da Natureza, já que por muitas vezes, os estudantes podem ter dificuldade em construir ações fundamentadas em aspectos interdisciplinares.

Nesse sentido, diante das premissas e concepções apresentadas e tendo em vista que o tema de pesquisa de mestrado de um dos autores é a Energia, este trabalho apresenta um recorte de uma oficina desenvolvida com os integrantes do Programa Institucional de Bolsa de Iniciação à Docência (PIBID) de um curso de Licenciatura em Ciências da Natureza de uma Universidade Federal do sul Brasil. O objetivo da oficina consistiu em abordar a temática Energia por meio de duas simulações/Experimentações disponíveis no software $\mathrm{PhET}^{1}$.

\title{
2. Metodologia
}

Metodologicamente esta pesquisa se caracteriza quanto a sua natureza como qualitativa, que segundo as concepções de Gil (2010, p. 134) pode ser entendida como um conjunto inicial de categorias que em geral "[...] é reexaminado e modificado sucessivamente, com vista em obter ideais mais abrangentes e significativas", levando em consideração todos os aspectos que possam enriquecer os resultados encontrados como esquemas, imagens, símbolos e narrativas. A pesquisa qualitativa também possibilita ao pesquisador uma profunda imersão referente ao tema estudado, explorado e investigado, considerando que sua atuação é essencial para os dados resultantes (CHIZZOTTI, 2008).

Para a abordagem da temática, escolheu-se as tecnologias digitais por meio da experimentação, pois atualmente é um dos recursos nos quais os professores devem se 
familiarizar diante de sua inserção em todas as áreas do conhecimento. Além disso, por ser uma opção que pode elucidar as transformações de Energia envolvendo várias situações cotidianas.

Vale destacar também que a experimentação emerge como um recurso eficiente para o levantamento de problemáticas estimulando a percepção de situações reais e contextualizadas por meio da investigação, análise e interpretação dos dados. Ainda proporciona que o professor problematize e incentive a criticidade dos indivíduos, bem como o caráter investigativo e a curiosidade (GUIMARÃES, 2009; JUNIOR et al., 2008).

Para aplicação da oficina, utilizou-se as simulações/experimentações denominadas "Energia na pista de skate" e "Formas de Energia e transformação" (Figura 1), disponíveis gratuitamente no software PhET.

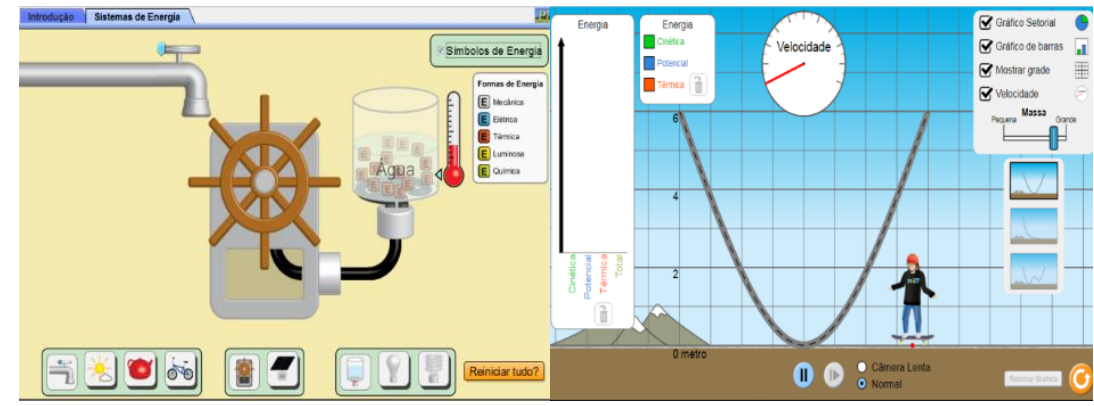

Figura 1 - Interface das experimentações utilizadas. Fonte: Phet (2019).

Para o desenvolvimento da oficina foram desenvolvidas cinco etapas, quais sejam: (1) aplicação do pré-teste, (2) discussão referente às TIC e os tipos de experimentação para o ensino de Ciências da Natureza, (3) apresentação do software escolhido, (4) mediação do conhecimento investigativo nas duas experimentações e (5) aplicação do pós-teste, conforme detalhado no Quadro 1.

Quadro 1 - Tamanhos e tipos de fontes.

\begin{tabular}{|c|c|c|}
\hline Etapa & Descrição & Objetivo \\
\hline \hline $1^{\text {a }}$ Etapa & Aplicação do pré-teste & $\begin{array}{c}\text { Analisar as concepções prévias dos acadêmicos } \\
\text { em relação às TIC e ao tema Energia. }\end{array}$ \\
\hline $2^{\text {a }}$ Etapa & Discussão referente às TIC e os tipos de & $\begin{array}{c}\text { Explanar sobre as TIC, e diferenciar e } \\
\text { caracterizar os tipos de experimentações. }\end{array}$ \\
\hline $3^{\text {a Etapa }}$ & Apresentação do software Phet & Explorar a interface do software e realizar as \\
& & \\
& & \\
\hline
\end{tabular}


RELACult - Revista Latino-Americana de Estudos em Cultura e Sociedade

\begin{tabular}{|c|c|c|}
\hline $4^{\text {a }}$ Etapa & $\begin{array}{c}\text { Mediação do conhecimento investigativo nas } \\
\text { experimentações }\end{array}$ & $\begin{array}{c}\text { Abordar a Energia e as transformações } \\
\text { encontradas em cada experimentação virtual com } \\
\text { o auxílio de recursos multimídia, distinguir os } \\
\text { tipos de Energia e apresentar algumas } \\
\text { conceituações para a temática. }\end{array}$ \\
\hline $5^{\text {a Etapa }}$ & Aplicação do pós-teste & $\begin{array}{c}\text { Avaliar os conhecimentos construídos após a } \\
\text { oficina. }\end{array}$ \\
\hline
\end{tabular}

Fonte: Autores (2019)

Os dados empíricos foram obtidos por meio de questionários abertos, utilizados como pré e pós-teste. O primeiro consistiu em analisar as concepções prévias dos acadêmicos em relação às TIC e a temática Energia, composto pelas seguintes questões: (1) O que significa a sigla TIC? (2) O que são tecnologias digitais? (3) Quais os tipos de experimentações que podem ser utilizadas para o ensino de Ciências da Natureza? (4) Qual a definição ou conceitos atribuídos ao tema Energia?

Além das indagações anteriores, no pós-teste foram inseridas mais três, quais sejam: (5) Quais as fontes de Energia que você conhece? (6) Quais as fontes de Energia que você reconhece nas atividades cotidianas? (7) Quais as formas de Energia reconhecidas por meio das experimentações utilizadas?

Os dados foram analisados com base na "Análise de Conteúdo" proposta por Laurence Bardin (2011), que consiste em três distintas etapas: (I) pré-análise, (II) exploração do material e (III) tratamento dos resultados, inferência e interpretação.

Na pré-análise, realizou-se a leitura flutuante dos questionários. Na fase de exploração do material, codificaram-se os acadêmicos com caracteres alfanuméricos A-1, A-2, A-3,... A14, sendo a letra "A" relacionada à palavra acadêmico e o numeral uma maneira de identificação para substituir o nome. As respostas foram transcritas fielmente para um programa de computador, a partir do qual, foram sintetizadas em três categorias de análise:

a) Satisfatória: formulou corretamente o conceito, apresentando exemplos quando necessário;

b) Parcialmente satisfatória: não formulou o conceito ou utilizou termos genéricos, contudo, citou exemplos;

c) Insatisfatória: errou a resposta ou não respondeu. 
Na última etapa, no tratamento das informações, elaborou-se gráficos e quadros que condensam e destacam as informações fornecidas para análise. A partir dos quais, realizou-se a inferência e a interpretação dos resultados.

\section{Resultados e Discussões}

Os pibidianos que participaram da pesquisa descrita neste trabalho pertenciam a três semestres diferentes, sendo seis $(43 \%)$ do $2^{\circ}$, três $(21 \%)$ do $4^{\circ}$ e cinco $(36 \%)$ do $6^{\circ}$. A faixa etária era compreendia entre 21 e 44 anos, sendo treze (93\%) mulheres e um (7\%) homem.

Na primeira questão, “O que significa a sigla TIC?”, dez (71\%) acadêmicos foram enquadrados na categoria satisfatória, pois responderam Tecnologia da Informação e Comunicação e quatro (29\%) foram insatisfatórios, pois não sabiam o significado. No pós-teste, todos acertaram. O Gráfico 1 apresenta um comparativo entre o pré e pós-teste da segunda questão, "O que são tecnologias digitais?".

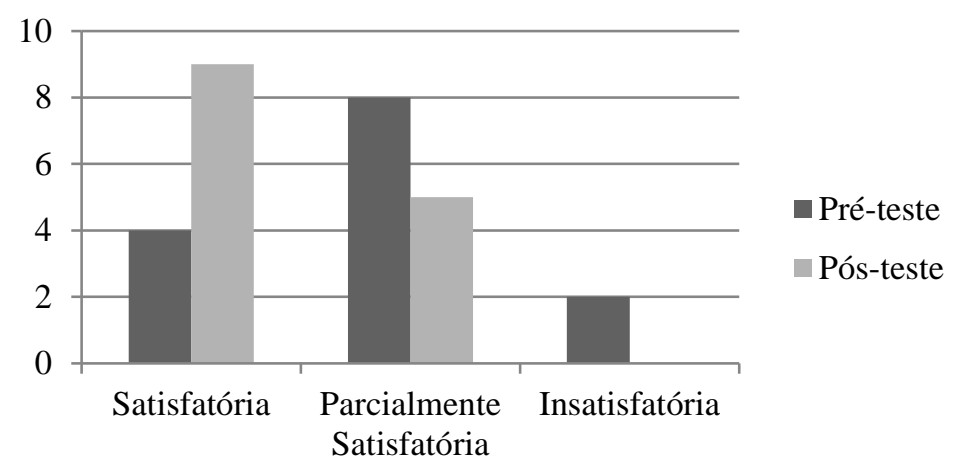

Gráfico 1 - Comparativo entre o pré e pós-teste da Questão 1. Fonte: Autores (2019).

$\mathrm{Na}$ categoria satisfatória inicialmente foram encontradas quatro (28\%) respostas, exemplificadas nos excertos a seguir: "São todas as ferramentas, interfaces que promovem e possibilitam a interação entre diferentes sujeitos" (A-7); "É um conjunto de tecnologias que servem para transformação de qualquer tipo de linguagem" (A-12); "São tecnologias que tem programação específica, possibilitando a interação entre diversas plataformas. Posso citar os aparelhos celulares, os computadores, notebooks, etc.” (A-5). No pós-teste, o número aumentou para nove $(64 \%)$.

A categoria parcialmente satisfatória englobou oito (57\%) respostas no pré-teste, nas quais, apontaram somente exemplos de tecnologias digitais, tais como: aparelhos celulares, 
televisores, microscópios, telescópios, notebooks, entre outros. No pós-teste, cinco (36\%) acadêmicos não conseguiram descrever o conceito.

Já a categoria insatisfatória, identificada somente no pré-teste, englobou dois acadêmicos (15\%) que não responderam. De acordo com Kruglianskas (1996), o conceito de tecnologias digitais pode ser entendido como um conjunto de conhecimentos necessários para se conceber, produzir e distribuir bens e serviços de forma competitiva. Nesse questionamento percebeu-se que, a maioria, apesar de conseguir identificar uma tecnologia digital, possuía dificuldade em elaborar o conceito.

O Gráfico 2 apresenta um comparativo entre o pré e pós-teste da terceira questão, "Quais os tipos de Experimentações que podem ser utilizadas para o ensino de Ciências da Natureza?”.

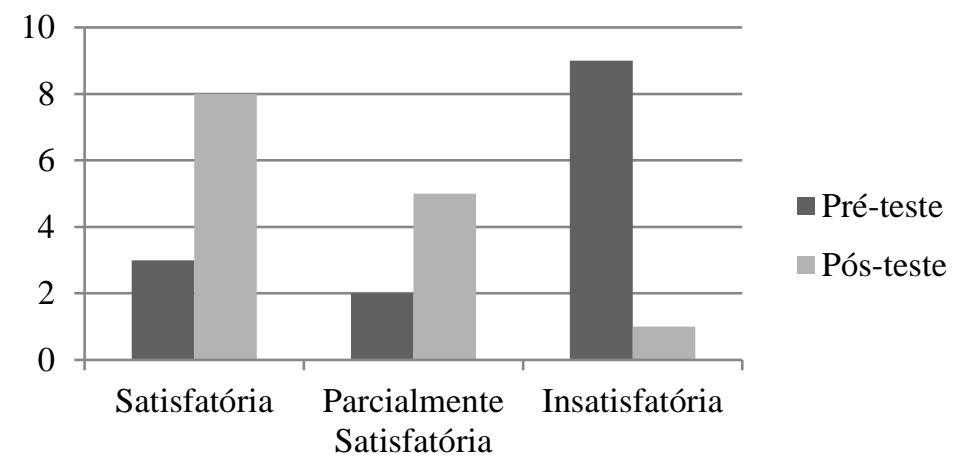

Gráfico 2 - Comparativo entre o pré e pós-teste da Questão 2. Fonte: Autores (2019).

$\mathrm{Na}$ categoria satisfatória reuniram-se aqueles que citaram e conceituaram as três classificações de experimentações, a exemplo do excerto: "São três tipos: Demonstrativa (o aluno apenas observa o professor), Verificativa (o professor entrega um roteiro para o aluno verificar) e Investigativa (o aluno quem faz tudo, o professor apenas media)" (A-6). No préteste foram três (21\%), enquanto que, no pós-teste aumentou para oito (57\%).

A categoria parcialmente satisfatória considerou os que citaram os tipos de experimentações, mas não explicaram o conceito, conforme trecho: "Entendi que são a Demonstração, Investigação e Verificação” (A-12). No pré-teste identificaram-se duas (15\%) menções, no pós-teste foram cinco (36\%).

A categoria insatisfatória foi expressiva no pré-teste, total de nove $(64 \%)$ respostas, no pós-teste, esse o número diminuiu para uma (7\%). Este resultado sugere que, antes da aplicação 
dessa oficina, grande parte dos acadêmicos ainda não conhecia os tipos de experimentações que podem ser abordadas nas aulas de Ciências da Natureza.

As experimentações entendidas como demonstrativas utilizam de atividades práticas, na qual servem para demonstrar determinados fenômenos como verdades estabelecidas. Neste tipo, os estudantes apenas observam ou um pequeno grupo participa da manipulação dos materiais e o professor realiza o desenvolvimento que pode ser empregado em qualquer instante da aula, para despertar a curiosidade ou apenas para comprovar o fenômeno. Algumas das vantagens dessas experimentações, geralmente, estão associadas a economia de tempo e materiais (ROSITO, 2008; KRASILCHIK, 2004).

As experimentações verificativas caracterizam-se pela atuação mutua do professor e do estudante. O professor tem como papel fiscalizar a atividade e diagnosticar possíveis erros a fim de repará-los. Para isto, fornece um roteiro fechado e estruturado, que deve ser seguido passo a passo. Ao estudante, cabe realizar a experimentação para posteriormente explicar os resultados encontrados. A facilidade para elaboração e explicação dos fenômenos verificados e a percepção da aprendizagem conceitual a partir das explicações feitas pelos estudantes, por parte do professor, são algumas das vantagens trazidas por este tipo de experimentação (OLIVEIRA, 2010).

As experimentações investigativas possibilitam que os estudantes atuem como protagonistas da execução, sendo o professor apenas o mediador que oferta materiais necessários para que planejem e interpretem livremente. Geralmente o professor elabora situações, questões problema ou hipóteses que serão refutadas ou comprovadas. Dentre as vantagens, destacam-se: a autonomia do estudante na formulação de hipóteses; a troca de ideias entre os pares aumentando a argumentação; proporciona a interação social levando a percepção de que a Ciência e o conhecimento são produzidos em conjunto; entre outras (GURIDI \& ISLAS, 1998; TONIDANDEL, 2008).

O Gráfico 3 apresenta um comparativo entre o pré e pós-teste da quarta questão, “Qual a definição ou conceito atribuído ao tema Energia?”. 


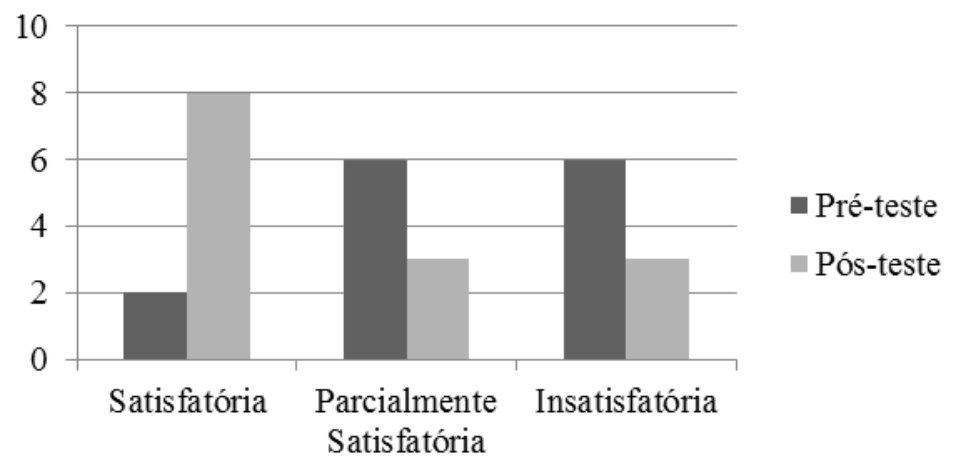

Gráfico 3 - Comparativo entre o pré e pós-teste da Questão 3. Fonte: Autores (2019).

No pré-teste apenas dois (13\%) souberam conceituar de forma correta a definição de Energia, sendo enquadrados na categoria satisfatória, são eles: “A Energia é a capacidade de realizar um trabalho" (A-4); "Está relacionada à capacidade de algo ou alguém realizar um trabalho" (A-9). No pós-teste foram oito (57\%), a exemplo dos excertos: "É a capacidade de realizar trabalho e também está associada a movimentação dos corpos" (A-11); "É a capacidade de realizar trabalho, o calor também é uma forma de Energia” (A-13).

$\mathrm{Na}$ categoria parcialmente satisfatória encaixaram-se as respostas que, apesar de não conceituarem o termo energia, possuem ligação com a temática, são algumas: "Está ligada ao movimento, trabalho e ação dos corpos" (A-3); "Capacidade de um corpo realizar movimento e força, pois a Energia está presente nas ações do nosso dia a dia” (A-8). No pré-teste foram seis $(43 \%)$ e três $(21 \%)$ no pós-teste.

A categoria insatisfatória, detectada em seis $(43 \%)$ respostas no pré-teste, demonstra que quase metade dos acadêmicos não sabia conceituar energia anteriormente à oficina. Acredita-se que a maioria não conseguiu responder corretamente devido à complexidade e abstração da temática.

Em consonância a esta constatação, em uma análise em livros didáticos, o estudo de Coelho (2014) apresenta as conceituações mais generalistas e rotineiramente utilizadas como “a Energia não pode ser criada, nem destruída, mas apenas transformada", ou, "Energia é a capacidade de realizar trabalho". A primeira conceituação apresentada delimita-se apenas aos fenômenos da natureza, já a segunda, torna-se insuficiente para atender a complexidade e totalidade do tema, limitando esta definição ao campo da física. Caso estas duas concepções forem desenvolvidas de forma isolada, o que no contexto da sala de aula acontece, poderá direcionar ao entendimento equivocado de que a Energia é vista como uma "substância". 
A Figura 2 apresenta uma nuvem de palavras que destaca as fontes de Energia citadas pelos acadêmicos a partir da quinta questão: “Quais as fontes de Energia que você conhece?”.

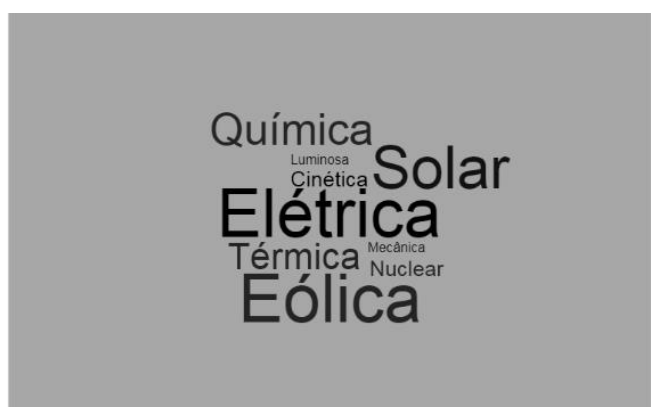

Figura 2 - Nuvem de palavras com as fontes de Energia citadas pelos acadêmicos. Fonte: Desenvolvida a partir do software Word it out.

Perceberam-se nove tipos de fontes de Energia mencionadas, sendo a Energia Elétrica (doze respostas), Energia Eólica (nove) e Energia Solar (sete) as mais expressivas. Poucos destacaram as fontes de Energia mais complexas como Energia Térmica (quatro), Energia Química (quatro), Energia Cinética (duas), Energia Nuclear (duas), Energia Mecânica (uma) e Energia Luminosa (uma). O Quadro 2 apresenta os exemplos citados pelos acadêmicos na sexta questão, "Quais as fontes de Energia que você reconhece nas atividades cotidianas?", respondida após a oficina.

\begin{tabular}{|c|c|c|}
\hline \multicolumn{1}{|c|}{ Quadro 2 - Respostas referentes a sexta questão. } \\
\hline \hline Égua fervendo na chaleira & Resposta & Forma de energia mais adequada \\
\hline \hline Andar de bicicleta & Energia térmica & Energia térmica \\
\hline Água das usinas hidrelétricas & Energia química & Energia cinética \\
\hline Raios solares & Energia elétrica & Energia luminosa \\
\hline Água aquecendo na jarra elétrica & Energia solar & Energia térmica \\
\hline Motor de um carro & Energia elétrica & Energia mecânica \\
\hline Trocas de temperatura (calor) & Energia mecânica & Energia térmica \\
\hline Caminhar & Energia térmica & Energia cinética \\
\hline O fogo que aquece a chaleira & Energia química & Energia térmica \\
\hline & Energia térmica & \\
\hline
\end{tabular}


RELACult - Revista Latino-Americana de Estudos em Cultura e Sociedade

\begin{tabular}{|c|c|c|}
\hline Placas solares & Energia solar & Energia luminosa \\
\hline Quebra de moléculas no organismo & Energia química & Energia química \\
\hline Carregar o celular & Energia elétrica & Energia elétrica \\
\hline Alimentos no micro-ondas & Energia elétrica & Energia elétrica \\
\hline Torres eólicas & Energia eólica & Energia cinética \\
\hline Movimentação das águas nas usinas & Energia cinética & Energia cinética \\
\hline Raios ultravioletas usados em fisioterapia & Energia luminosa & Energia luminosa \\
\hline Locomotiva & Energia mecânica & Energia térmica \\
\hline
\end{tabular}

Fonte: Autores (2019).

Alguns acadêmicos destacaram mais de um exemplo em suas respostas. Dos 19 citados, onze (58\%) estavam corretos e oito (42\%) equivocados, sinalizando a necessidade de retomar em oficinas futuras os tipos de transformações das energias. Principalmente a nomenclatura, visto que alguns utilizaram termos não científicos, por exemplo, denominar energia luminosa como solar.

$\mathrm{Na}$ última questão, "Quais as formas de Energia reconhecidas por meio das experimentações?", percebeu-se a menção de sete tipos de formas de Energia tais como: Energia Cinética (20\%); Energia Térmica (17\%); Energia Luminosa (15\%); Energia Química (13\%); Energia Mecânica (13\%); Energia Potencial (12\%) e Energia Eólica (10\%). Constatouse que as formas de Energia destacadas pelos acadêmicos correspondem às abordadas nas experimentações virtuais.

As experimentações oportunizaram a exploração de diversas transformações de Energia a partir das cinco formas de Energia disponibilizadas, sendo que na primeira experimentação, "Formas de Energia e Transformação", encontravam-se a Energia Mecânica, a Energia Elétrica, a Energia Térmica, a Energia Luminosa e a Energia Química. A Figura 3 elucida uma das possibilidades destas transformações. 

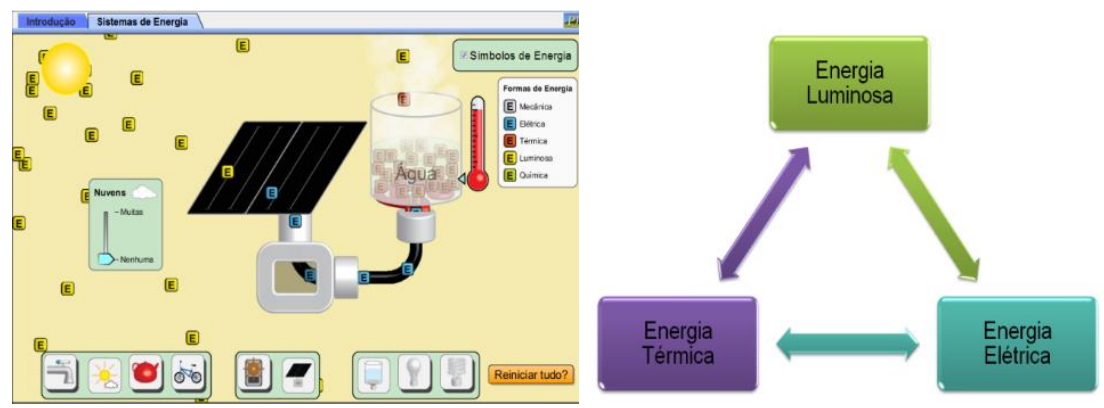

Figura 3 - Experimentação 1 e as transformações de Energia Fonte: Autores (2019)

A Figura 3 mostra as transformações da Energia Luminosa do sol captada pelas placas solares em Energia Elétrica que aquece a água contida no recipiente. Nesta experimentação virtual também foi possível explanar sobre a perca de Energia para o meio externo.

Já a segunda experimentação, "Energia na pista de skate", oportunizou a abordagem de três tipos de formas de Energia: Energia Potencial, Energia Térmica e Energia Cinética, exposta na Figura 4.
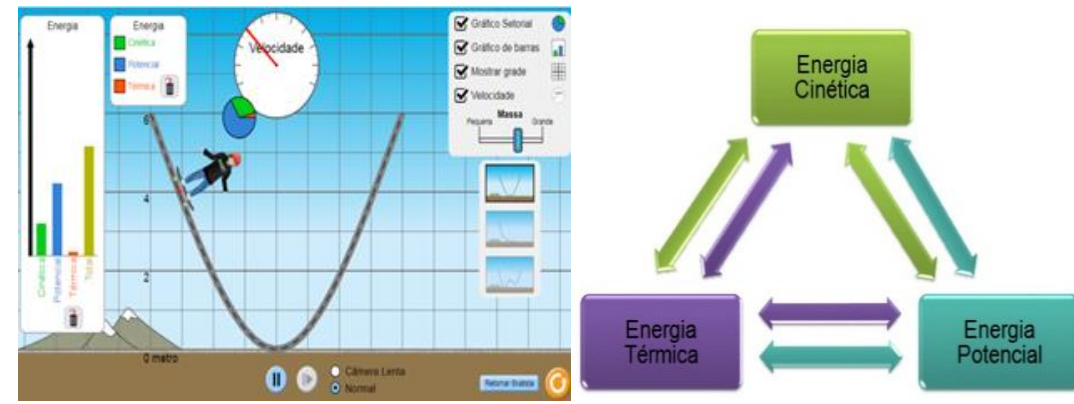

Figura 4 - Experimentação 2 e as transformações de Energia Fonte: Autores (2019)

A Energia Térmica do skatista é representada no gráfico de barras da simulação pela cor vermelha, já a Energia Cinética é demonstrada pela cor verde e a Energia Potencial é demarcada pela cor azul. Ao realizar a experimentação percebe-se que o gráfico do simulador se altera constantemente permitindo assim a visualização das transformações das Energias supracitadas. A cor amarela do gráfico da simulação demonstra que a Energia não se perde para o meio, mas sim se transforma em outras formas. 


\section{Considerações finais}

As tecnologias digitais estão cada vez mais presentes em nosso cotidiano, e as vantagens nas quais estas podem trazer são consideradas diversas, logo, inseri-las no contexto do ambiente escolar é uma realidade inegável. Desde o ano de 1998 os documentos oficiais (PCN) já faziam menção ao uso das TIC para o desenvolvimento das aulas em todas as áreas do conhecimento.

Os resultados encontrados nas análises do pré-teste em relação ao pós-teste sugerem que a utilização das TIC por meio de experimentações virtuais pode favorecer o entendimento de temas abstratos como a Energia, já que por meio do PhET foi possível investigar o comportamento das formas de Energia e suas transformações com vários exemplos cotidianos.

Outro ponto que merece ser ressaltado se refere à participação e interação dos acadêmicos nas etapas da Oficina, pois as ideias e concepções eram partilhadas durante a exploração das experimentações virtuais. A autonomia dos acadêmicos ao utilizarem o software despertou a curiosidade e instigou os mesmos na busca das respostas que emergiram durante a oficina, a exemplo: como uma forma de Energia pode se transformar em outra? Porque a Energia Luminosa obtida do Sol não girava o moinho, não gerando assim nenhuma transformação de Energia? Entre outras questões trazidas por eles ao longo da oficina.

Considera-se que a utilização das tecnologias quando empregadas de forma adequada podem favorecer a contextualização e compreensão de fenômenos abstratos relacionados à área de Ciências da Natureza. Por este motivo, pretende-se seguir as pesquisas em torno da temática Energia e também realizar uma segunda oficina com o mesmo grupo de pibidianos com o intuito de propiciar esclarecimentos diante das questões respondidas inadequadamente e contribuir na construção dos saberes conjuntos. Este trabalho tem apoio financeiro da FAPERGS.

\section{Referências}

ANDRE, M. E. D. A. Estudo de caso: seu potencial na educação. Cadernos de Pesquisa, [S.1.], n. 49, p. 51-54, 1984. ISSN 0100-1574.

BARDIN, L. Análise de conteúdo. São Paulo: Edições 70, 2011.

BRASIL. Ciências da Natureza, Matemática e suas Tecnologias. Parâmetros Curriculares Nacionais - Ensino Médio: Orientações Educacionais Complementares aos parâmetros Curriculares Nacionais. Brasília: MEC/SEMTEC, 2002.

COELHO, R. L. On the Concept of Energy: Eclecticism and Rationality. Science \& Education, [S.1.], v. 23, n. 6, p. 1361-1380, 2014. ISSN 0926-7220. 
CHIZZOTTI, A. Pesquisa qualitativa em ciências humanas e sociais. Petrópolis - RJ: Vozes, 2008.

GIL, A. C. Como elaborar projetos de pesquisa. 5. ed. São Paulo: Atlas, 2010.

GASPAR, A. Experiências de Ciências. São Paulo: Ed. Ática, 2009.

GUIMARÃES, C. G. Experimentação no Ensino de Química: Caminhos e Descaminhos Rumo à Aprendizagem Significativa. Revista Química Nova na Escola, [S.1.], v. 31, n. 3, p. 198-202, 2009. 2175-2699. Disponível em: http://qnesc.sbq.org.br/online/qnesc31_3/08-RSA4107.pdf. Acesso em: 10 julho 2019.

GURIDI, V.; ISLAS, S. M. Guías de laboratorio tradicionales y abiertas em Física elemental: propuesta para diseñar guías abiertas y estudio comparativo entre el uso de este tipo de guías y guías tradicionales. Revista Investigações em Ensino de Ciências, Porto Alegre, n. 3, v. 3, p. 203-220, 1998. ISSN 1518-8795. Disponível em:

https://www.if.ufrgs.br/cref/ojs/index.php/ienci/article/view/618/406. Acesso em: 10 julho 2019.

JUNIOR, W. E. F. et al. Experimentação Problematizadora: Fundamentos Teóricos e Práticos para a Aplicação em Salas de Aula de Ciências. Revista Química Nova na Escola, [S.1.], n. 30, p. 38-41, nov., 2008. 2175-2699. Disponível em: http://qnesc.sbq.org.br/online/qnesc30/07PEQ-4708.pdf. Acesso em: 10 julho 2019.

KRASILCHIK, M. Prática de Ensino de Biologia. São Paulo: Moderna. 2004.

KRUGLIANSKAS, I. Tornando a pequena e média empresa competitiva. São Paulo: Instituto de Estudos Gerenciais e Editora, 1996.

MENDES, A. TIC - Muita gente está comentando, mas você sabe o que é? Revista Abril, Rio de Janeiro, [s.n.], mar., [s.p.], 2008. Disponível em: http://imasters.com.br/artigo/8278.

Acesso em: 10 julho 2019.

MORTIMER, E. F.; AMARAL, L. O. F. Quanto mais quente melhor: calor e temperatura no ensino de termoquímica. Revista Química Nova na Escola, [S.1.], n. 7, p. 30-34, maio, 1998. 2175-2699. Disponível em http://qnesc.sbq.org.br/online/qnesc07/aluno.pdf. Acesso em: 10 julho 2019.

OLIVEIRA, J. R. S. Contribuições e abordagens das atividades experimentais no ensino de ciências: Reunindo elementos para a prática docente. Acta Scientiae, Canoas, v.12, n. 11, p. 139-153, jan./jun., 2010. ISSN 2178-7727 Disponível em: http://www.periodicos.ulbra.br/index.php/acta/article/view/31. Acesso em: 10 julho 2019.

PONTE. J. P. Tecnologias de Informação e Comunicação na Formação de Professores: Que desafios? Revista Iberoamericana de Educación, n. 24, p. 63-90, 2000. ISSN 1681-5653. Disponível em: https://rieoei.org/historico/documentos/rie24a03.htm. Acesso em: 10 julho 2019. 
PHET. Experimentação Simulação Formas de Energia e Transformação. Disponível em: https://phet.colorado.edu/pt_BR/simulation/legacy/energy-forms-and-changes. Acesso em: 10 julho 2019.

PHET. Experimentação Energia na Pista de Skate. Disponível em:

https://phet.colorado.edu/pt_BR/simulation/energy-skate-park-basics. Acesso em 10 julho 2019.

ROSITO, B. A. O ensino de ciências e a experimentação. In: MORAES, R. (Org.).

Construtivismo e ensino de ciências: reflexões epistemológicas e metodológicas. 3. ed. Porto Alegre: EDIPUCRS, 2008, p. 195-208.

SOUZA, V. C. de A.; JUSTI, R. Estudo da utilização de modelagem como estratégia para fundamentar uma proposta de ensino relacionada à energia envolvida nas transformações químicas. Revista Brasileira de Pesquisa em Educação em Ciências, Minas Gerais, v. 10, n. 2, p. 1-26, 2010. ISSN 1984-2686 Disponível em:

https://periodicos.ufmg.br/index.php/rbpec/article/view/2176. Acesso em: 10 julho 2019.

TAVARES, et. al. Um estudo sobre a "TIC" e o Ensino da Química. Revista Gestão, Inovação e Tecnologias, São Cristóvão, v. 3, n. 5, p. 155-167, 2013. ISSN 2237-0722. Disponível em: http://www.revistageintec.net/index.php/revista/article/view/296/346. Acesso em: 10 julho 2019.

TONIDANDEL, S. Escrita argumentativa de alunos do ensino médio alicerçada em dados empíricos obtidos em experimentos de Biologia. 2008. $171 \mathrm{f}$. Dissertação (Mestrado em Educação) -. Faculdade de Educação, Universidade de São Paulo, São Paulo, 2008. 